\title{
Perfil de estudantes ingressantes de um curso de enfermagem do Sul do Brasil: caracterização dos hábitos de leitura e estudo
}

\author{
First year undergraduate students profile of a nursing course of \\ Southern Brazil: characterization of the habits of reading and study
}

\author{
Aline Korki Arrabal Garcia ${ }^{1}$; Aluana Moraes ${ }^{2}$; Maria Helena Dantas de \\ Menezes Guariente ${ }^{3}$
}

\begin{abstract}
Resumo
O Curso de Enfermagem da Universidade Estadual de Londrina possui uma metodologia de ensino inovadora por meio do currículo integrado, baseada na problematização, sendo proposta ao aluno a busca da autonomia no estudo e o compromisso em relação aos meios de aprendizagem. Objetivou-se descrever a prática de leitura e estudo dos alunos ingressantes do curso de enfermagem da Universidade Estadual de Londrina. Trata-se de pesquisa documental, descritiva e retrospectiva com abordagem quantitativa, com egressos do curso de enfermagem. Para a coleta de dados foi utilizado questionários respondidos pelos estudantes ingressantes nos anos 2000, 2005 e 2010 no curso. Identificou-se dos 164 ingressantes que $91,5 \%$ são do sexo feminino e $97,6 \%$ solteiras, com idade entre 16 a 18 anos $(45,1 \%)$. O hábito de leitura esteve presente em $81,7 \%$ dos pesquisados, sendo que $49,4 \%$ relataram apresentar facilidade na redação de textos e 57,3\% facilidade parcial na interpretação de textos. Os estudantes (64\%) ainda expressaram preferência por estudar sozinho, sendo a leitura silenciosa a forma de estudo mais relatada. A caracterização dos dados poderá subsidiar a gestão do curso e os professores no sentido de fomentar o desempenho acadêmico dos estudantes de enfermagem para o alcance do perfil profissional delineado.
\end{abstract}

Palavras chave: Ensino humanizado. Formação médica. Medicina paliativa. Relação médico-paciente.

\begin{abstract}
The Integrated Curriculum methodology, from the Nursing Program in State University of Londrina is based on problematization, being proposed to the student the achievement of autonomy in studies and the commitment according to the learning methods. This research aimed to describe the habit of reading and studying from learners entering nursing school in the State University of Londrina. It is a documental research in quantitative approach. To the survey, questionnaires were elected, from students joining the course in 2000, 2005 and 2010. It was identified that from the 164 entrants, $91.5 \%$ were female, $97.6 \%$ single, 16 to 18 years old (45.1\%). The habit of reading was present in $81.7 \%$ of the examined, $49.4 \%$ mentioned finding easy to write texts and $57.3 \%$ had partial ease in interpreting texts. There is a preference for studying alone among $64.0 \%$ of the students and the silent reading was the most mentioned way of studying. The data characterization may subsidize the course management and teachers to Foster the academic performance of nursing students to achieve the professional profile outlined.
\end{abstract}

Keyword:Education in nursing. Curriculum. Reading.

\footnotetext{
${ }^{1}$ Enfermeira, especialista em enfermagem perioperatória. Mestranda do Programa de Pós-Graduação em Enfermagem da Universidade Estadual de Londrina. E-mail: aluanamoraes@hotmail.com

2 Especialista em Gerenciamento de Enfermagem em Clínica Médica e Cirúrgica. Mestranda do Programa de Pós-Graduação em Enfermagem da Universidade Estadual de Londrina. E-mail: aluanamoraes@hotmail.com

${ }^{3}$ Doutora em Enfermagem Enfermagem Fundamental pela Escola de Enfermagem de Ribeirão Preto da Universidade de São Paulo Professora do Programa de Pós-Graduação em Enfermagem da Universidade Estadual de Londrina. aluanamoraes@hotmail.com
} 


\section{Introdução}

O mercado de trabalho e as instituições de saúde têm requisitado de seus colaboradores um perfil profissional em constante desenvolvimento, com o intuito de acompanhar as inovações tecnológicas, com potencial para resolução de problemas, bem como a capacidade de negociação e perfil proativo. As organizações de saúde também exigem dos enfermeiros qualidades como inovação, criatividade, agilidade e capacidade de decidir assertivamente, agregando deste modo valor às organizações e ao indivíduo (MARTINS et al., 2006).

As Diretrizes Curriculares Nacionais (DCN), para os cursos de graduação em enfermagem, orientam que a formação curricular do enfermeiro contemple a aquisição de competências e habilidades, considerando o quadro epidemiológico da região e do país de origem (MEIRA; KURCGANT, 2008).

Neste contexto da formação profissional, a Associação Brasileira de Enfermagem (ABEn) empreitou, após acirrada discussão permeada pelas conjecturas políticas, educacionais e sociais, uma proposta que delineia a formação de enfermeiros críticos-reflexivos, compromissados com a transformação, tendo como princípio o exercício da relação teoria-prática a partir da realidade (CHIRELLI, 2002).

No cenário da educação superior no país, a partir da Lei de Diretrizes Bases (LDB), concretizou-se, em 2001, com o Parecer no 1133 do CNE/CES, a necessidade de implementação da articulação entre Educação Superior e Saúde, objetivando a formação geral e específica dos egressos, com ênfase na promoção, prevenção, recuperação e reabilitação da saúde. Com a aprovação da Resolução CNE/CES N ${ }^{\circ}$ 03 de 7/11/2001, definiu-se as Diretrizes Curriculares Nacionais para o Curso de Graduação em Enfermagem (DCENF) (FERNANDES et al., 2005).

A resolução CNS/CNE n ${ }^{\circ}$ 3/2001 traça o perfil do egresso a ser formado, descrevendo-o como generalista, humanista, crítico e reflexivo, devendo o profissional possuir rigor cientifico, intelectual, baseado em princípios éticos, sendo capacitado a distinguir e intervir sobre situações e problemas de doenças (BRASIL, 2001).

A enfermagem é uma pratica social, política e historicamente determinada, cujo objetivo primordial é o cuidado ao ser humano em todos os ciclos da vida, contribuindo deste modo para a promoção, prevenção, recuperação e reabilitação da saúde (GARANHANI et al., 2013).

As escolas de Enfermagem buscaram então atender aos sinais dos tempos, como as exigências profissionais apresentadas na Lei de Diretrizes e Base e promoveram mudanças curriculares. O currículo de Enfermagem deve proporcionar uma educação que possibilite à pessoa pensar, agir, saber, desejar buscar conhecimento, duvidar da verdade e apreciar valores da profissão.

O curso de Enfermagem da Universidade Estadual de Londrina, sintonizado com as mudanças nas áreas da saúde e educação, tem, ao longo de sua existência, impulsionado mudanças curriculares e em 2000 implantou o Currículo Integrado. Esta modalidade curricular visa à formação do enfermeiro generalista.

O Currículo Integrado é construído coletivamente, conduzindo assim a integração dos conteúdos do ciclo básico e do profissionalizante, teoria e prática, possibilitando a abordagem de temas transversais como ética, humanismo, comunicação, trabalho em equipe, cuidado em enfermagem, entre outros. Trata-se de um projeto organizado em módulos integrados e não mais em disciplinas (GARANHANI et al., 2013).

Anualmente, o Curso de Enfermagem utiliza o sistema seriado anual, com 4.152 horas e oferece 60 vagas para o ingresso dos candidatos selecionados pelo vestibular. É ministrado em período integral, com duração de quatro anos (KIKUCHI; GUARIENTE, 2014).

Descreve o projeto curricular que, deve ser priorizada aos futuros profissionais, a formação 
generalista, ética, humanista, crítica e reflexiva, voltada ao desenvolvimento de competências e habilidades gerais, abrangendo a atenção à saúde, tomada de decisões, comunicação, trabalho em equipe, liderança, administração/gerenciamento e a educação permanente (KIKUCHI; GUARIENTE, 2014).

Contudo, para forjar a formação pretendida há que se considerar que os alunos que chegam à universidade vêm, em grande parte, de um sistema de ensino que centralizou os seus esforços no ensino fragmentado por disciplinas, tendo como tônica a memorização de conteúdo. A forma de estudar como o hábito da leitura são desempenhos frágeis pela formação recebida até então (ANASTASIOU; ALVES, 2012).

Os princípios pedagógicos do Currículo Integrado alicerçam-se na gênese da crise paradigmática da ciência e da educação, onde a discussão em pauta é a necessidade de extrapolar a prática que reafirma a fragmentação do conhecimento, derrubando deste modo a fronteira das especialidades das disciplinas e buscando uma integração totalizadora (GARANHANI et al., 2013).

A metodologia do Currículo Integrado baseia-se na problematização, que implica na proposição do exercício de autonomia, criatividade, responsabilidade social e do compromisso do aluno em relação aos métodos de aprendizagem (GARANHANI et al., 2013).

O papel do docente neste momento é de orientar o processo de aprendizagem, mediante promoção da aprendizagem significativa, estimulando o raciocínio do aluno durante a problematização. Em contrapartida, o papel do estudante é o de sujeito ativo no processo de construção do seu próprio conhecimento (KIKUCHI; GUARIENTE, 2014).

Neste espeque, este curso visa a formação de profissionais generalistas e que estejam preparados para atender pacientes nos programas de saúde em nível primário, secundário ou terciário, exercendo suas funções com consciência, autonomia, compromisso profissional e responsabilidade ética, propondo- se ainda a contribuir para o desenvolvimento da profissão, através do ensino, pesquisa, participação em entidades organizadas e no exercício da cidadania (KIKUCHI; GUARIENTE, 2014).

Assim sendo, para que seja possível o desenvolvimento do aluno no Currículo Integrado, alcançando todas as habilidades e atribuições esperadas, é necessário que o universitário considere a leitura como um hábito diário e prazeroso, pois ela está presente no dia-a-dia dos seres humanos e é por meio dela que adquirimos grande parte do nosso conhecimento. Na formação universitária principalmente, ela é considerada uma das habilidades essenciais, o principal acesso ao conteúdo de diversas disciplinas. A falta de hábito da leitura pode acarretar dificuldades para o aluno no seu aprendizado e na sua visão crítico-reflexivo.

Posto isso, na sociedade em que vivemos, no qual a capacidade de processar informações deixou de ser apenas habilidade intelectual para transformarse em condição de sobrevivência econômica, o indivíduo que for privado das ferramentas da leitura e da escrita está sujeito à marginalização pessoal, profissional e social. Desta forma, a leitura e a escrita não se limitam ao papel de possibilitar o acesso à informação, tornando-se verdadeiras atividades cognitivas que promovem e facilitam o desenvolvimento e aperfeiçoamento de outras habilidades, como a criatividade e o espírito crítico, sendo essas necessárias ao exercício da cidadania e à plena realização do potencial intelectual e afetivo de todo ser humano (SAMPAIO; SANTOS, 2002).

Tem-se que a leitura permite a ampliação de horizontes e de pensamentos, enriquecendo o vocabulário e facilitando o processo de comunicação. Desta maneira pode-se traçar um paralelo entre o hábito de ler proveitoso e o sucesso profissional, visto que a leitura é fundamental para o aprofundamento dos conhecimentos (ARRUDA et al., 2012).

Destaca-se que algumas pesquisas brasileiras com universitários ingressantes, têm caracterizado as habilidades básicas que interferem no desempenho 
acadêmico, definindo-as como aspectos referentes aos conhecimentos processuais que englobam a compreensão da leitura, o nível de conhecimentos gerais, a atualização e a capacidade de raciocínio. Estes fatores são necessários no aprendizado de novos conteúdos, exigindo do universitário a ativação dos processos de apreensão, retenção e contextualização de novas informações obtidas por meio da leitura. E mais uma vez, os resultados encontrados mostram que a probabilidade de ser bem-sucedido na universidade está diretamente relacionada à maturidade do estudante enquanto leitor (SILVA; SANTOS, 2004).

A investigação de tal situação, visando o diagnóstico do hábito de leitura e estudo entre estes estudantes, pode trazer indicadores que levem os professores a conhecer os estudantes e promover estratégias com o objetivo de otimizar o processo de ensino-aprendizagem e consequentemente, a formação pretendida por este curso.

Neste sentido, o objetivo da presente pesquisa, foi descrever, entre os alunos ingressantes do curso de Enfermagem dos anos de 2000, 2005 e 2010, o perfil sociodemográfico, o hábito e as preferências de leituras, bem como a percepção dos pesquisados sobre a facilidade em escrever e interpretar textos e ainda, como se dá o hábito de estudo quanto às variáveis: local, ambiente, método e preferências.

\section{Método}

Trata-se de um estudo do tipo descritivo, retrospectivo, documental, com abordagem quantitativa, realizado com estudantes de um curso de enfermagem do norte do Paraná. Atualmente o curso oferece 60 vagas para o ingresso dos candidatos selecionados por meio de vestibular e SISU (Sistema de Seleção Unificado), sendo ministrado em período integral, com duração de quatro anos (UNIVERSIDADE ESTADUAL DE LONDRINA, 2015).

O objeto de estudo consiste em questionários, respondidos por estudantes de enfermagem no período de ingresso ao curso, dos anos 2000, 2005 e 2010. Esse questionário é elaborado por professores do curso, que tem como objetivo conhecer o perfil dos alunos ingressantes que escolheram a enfermagem como profissão, contendo as seguintes informações, tais como: sexo; idade; procedência; residência; condições de saúde; perfil socioeconômico; formação acadêmica; hábitos de estudos; hábitos de lazer; características pessoais; entre outras.

A amostra foi conformada através dos seguintes critérios de inclusão: preenchimento do questionário no momento do ingresso do curso, questionários respondidos nos anos de 2000, 2005 e 2010. Esses anos foram escolhidos devido à completude dos dez anos de implantação do Currículo Integrado em Enfermagem.

A coleta de dados ocorreu no período de março a junho de 2013, por uma única pesquisadora, estudante de enfermagem em término da graduação. Para a coleta de dados foi utilizada um instrumento elaborado pela própria pesquisadora, este evidenciando as variáveis sócias demográficas, econômicas, familiares, educacionais e hábitos de estudo. Após isso, os dados foram tabulados e organizados pelo programa Microsoft Office Excel 2007, receberam tratamento estatístico descritivo simples por meio da mesma ferramenta tecnológica.

Por se tratar de pesquisa documental, sem envolvimento direto com seres humanos, foi elaborado Termo de Sigilo e Confidencialidade, protocolado junto à Coordenação do Colegiado de Curso, onde a pesquisadora se comprometeu a: não utilizar as informações confidenciais a que teve acesso, para gerar benefício próprio exclusivo e/ou unilateral, presente ou futuro, ou para o uso de terceiros; Não efetuar nenhuma gravação ou cópia da documentação confidencial a que teve acesso; Não apropriar-se para si ou para outrem de material confidencial e/ou sigiloso da tecnologia que foi disponível; Não repassar o conhecimento das informações confidenciais, responsabilizandose por todas as pessoas que vierem a ter acesso às 
informações, por seu intermédio, e obrigando-se, assim, a ressarcir a ocorrência de qualquer dano e/ou prejuízo oriundo de uma eventual quebra de sigilo das informações fornecidas.

O Termo de Sigilo e Confidencialidade foi datado e assinado pela pesquisadora, bem como disponibilizado à Coordenação do Colegiado do Curso, para eventuais dúvidas e esclarecimentos no que tange a pesquisa, não havendo pagamento de qualquer espécie de bônus à instituição pela pesquisadora. Para a realização desse estudo foi considerado todas as normas preconizadas pela Resolução 466/2012 do Conselho Nacional de Saúde. A referente pesquisa foi submetida ao comitê de ética em pesquisa em seres humanos da Universidade Estadual de Londrina aprovada sob parecer 339/2011 e CAAE 0323.0.288.000-11.

\section{Resultados e Discussão}

Responderam ao questionário 57 alunos no ano de 2000 e 2005, já no ano de 2010 foram 50 alunos. Desta forma, perfaz-se o total de 164 alunos que estão dentro dos critérios de inclusão para a pesquisa. A justificativa para o total de alunos a cada ano ser inferior a 60 se dá a alguns fatores, tendo como principal, o fato do questionário ter sido aplicado na primeira semana de aula do curso, e neste momento, muitos alunos não comparecem a aula, ou ainda devido ao fato de alguns estudantes serem convocados somente em outras chamadas, após a primeira semana de aula, ficando inviável o preenchimento deste questionário. Ainda o número de matriculados não é igual aos que iniciam as atividades curriculares, já que alguns passam em outras faculdades ou desistem do curso antes mesmo do seu ingresso.

Foi identificado que o perfil do aluno ingressante no curso de enfermagem da UEL é semelhante as demais universidades do Brasil, sendo o sexo feminino a maioria dos estudantes perfazendo um total de $91,5 \%$, este resultado está relacionado a imagem histórica da profissão ser feminina (WETTERICH; MELO, 2007).
Historicamente a literatura demonstra que a predominância dos trabalhadores nos hospitais é do sexo feminino, principalmente na enfermagem, explicada em função do arquétipo, atribuído às mulheres. Fato que também é elucidado em várias culturas, onde a assistência e higienização dos doentes são consideradas como extensão do trabalho feminino. Além disso, considera-se ser um traço estrutural das atividades de saúde, a preponderância da força do trabalho feminil nas atividades que envolvem o trato e o cuidado com as pessoas (MARTINS et al., 2006).

A idade dos estudantes variou de 16 a 39 anos, sendo que $45,1 \%$ se encontravam na faixa dos 16 aos 18 anos quando ingressaram na faculdade. Segundo alguns autores a presença de acadêmicos mais jovens no curso pode ser considerada como um fator positivo, à medida que os jovens profissionais poderão trazer oportunidades mais cedo, gerando perspectivas de crescimento e progresso. Em contrapartida, quando estes alunos ingressarem no mercado de trabalho, poderão enfrentar compromissos e desafios inerentes à profissão, além de terem dúvidas se esta é a profissão que eles realmente desejam (BRITO; BRITO; SILVA, 2009).

Quanto ao estado civil, observou-se que 97,6\% dos estudantes eram solteiros, o que demonstra consonância com outros estudos, que destacam como causa o fator de as mulheres estarem valorizando mais a carreira profissional e deixando o casamento em segundo plano. Outros citam o fato do curso ser integral e apresentar uma grade curricular intensa, o que dificulta o casamento. O último argumento é pela pouca idade dos discentes, não tendo idade para casar segundo os padrões da sociedade moderna (SPÍNDOLA; MARTINS; FRANCISCO, 2008; WETTERICH; MELO, 2007).

Em relação à existência de paternidade e maternidade, foi observado que $94,5 \%$ não possuíam filhos, somente $5,5 \%$ possuíram descendentes. A ocorrência desse fato pode estar vinculada ao perfil dos estudantes, pois são jovens, 
solteiros, priorizam sua formação profissional e inserção no mercado de trabalho (SPÍNDOLA; MARTINS; FRANCISCO, 2008).

Sobre o número de irmãos que os ingressantes possuíam 76,9\% apresentaram de um a dois irmãos. Em relação à religião, a católica foi a referida por $67,7 \%$. Sobre a procedência dos alunos, $61,6 \%$ vieram de outras cidades, porém é válido lembrar que muitos residem em cidades vizinhas à Londrina, e realizam o trajeto à faculdade todos os dias. $\mathrm{O}$ fato dos alunos serem de outras localidades é relevante, pois indica uma forte inserção dessa instituição no mercado de trabalho e, estes futuros enfermeiros terão uma formação distante da realidade de seu município, considerando a prática profissional, o que poderá limitar sua atuação, caso venham a exercê-la em seu local de origem (BRITO; BRITO; SILVA, 2009).

Outra observação foi a de que 97,6\% dos alunos participantes não tem vínculo empregatício, isso se deve ao fato do curso ser em período integral, o que dificulta a inserção no mercado de trabalho. Consigna-se que do número reduzido dos estudantes que trabalhavam, sua grande maioria atuava em outras categorias de enfermagem, alunos que exercem atividades remuneradas em outras categorias de enfermagem (auxiliares e técnicos), procuram um curso superior sempre na tentativa de melhoria da atividade e do próprio reconhecimento profissional, já que essas categorias são menos remuneradas e pouco valorizadas no setor da saúde (WETTERICH; MELO, 2007).

Algumas pesquisas mencionam que o trabalho opera como fator de influência desfavorável no rendimento acadêmico, representado pela falta de tempo para o estudo, dificuldade de assimilar a matéria e falta de concentração em sala de aula. Ainda atribuem ao trabalho a queda na produtividade, susceptibilidade a doenças, frequência constante ao médico e abuso no uso de medicações (BRITO; BRITO; SILVA, 2009).

No entanto, sem vínculo empregatício fica impossível o próprio sustento, revelando que
$88,40 \%$ dos ingressantes dependem da renda de seus pais. No mesmo sentido, uma pesquisa realizada no Rio Grande do Sul, sobre a qualidade de vida dos acadêmicos de enfermagem, demonstra que o nível de renda familiar é de aproximadamente 5 a 10 salários mínimos, que se faz semelhante aos acadêmicos da Universidade Estadual de Londrina, no Estado do Paraná, estudados nesta pesquisa, que ratificam que $66,30 \%$ apresentam essa renda mensal (EURICH; KLUTHCOVSKY, 2008).

Dos alunos participantes da pesquisa, observouse que nos anos de estudo, 91,5\% dos ingressantes utilizavam o ônibus como o meio de transporte principal. A porcentagem de ingressantes que detém o benefício do computador em casa foi de $64,6 \%$, e dos que possuem o domínio da informática foi de $65,4 \%$. Assim, a cada ano essas porcentagens vêm aumentando, relacionando-se este resultado com as inúmeras ofertas de informações, comunicação, aprendizagem, entretenimento e lazer depois da chegada das tecnologias digitais, principalmente com a popularização do computador com acesso à internet. Certamente estas tecnologias têm influenciado comportamentos e estimulado atividades intelectuais voltadas à nova realidade cultural, hoje bastante marcada pela utilização das ferramentas digitais. Por essa razão, a importância das tecnologias no aprendizado da geração $\mathrm{Y}$, que repercutem de forma expressiva no processo de ensino dos docentes. Com a entrada da tecnologia de forma tão natural na vida dos alunos, elas podem servir como forma de facilitar ou obstruir seu processo na aquisição de conhecimento (XAVIER, 2011).

Dos discentes participantes, o hábito de leitura esteve presente em $81,7 \%$ dos pesquisados. O tipo de leitura realizada foi para $72,3 \%$ em revistas, seguido por $60,4 \%$ em livros literários. A escrita foi mencionada por $49,40 \%$ como aspecto de facilidade na sua elaboração e para $57,3 \%$ mediana facilidade na interpretação de textos. Estes dados são de extrema importância ao analisarem-se as pesquisas, que apontam como dificuldade mais preocupante, demonstradas pelos universitários 
dos primeiros anos, as relativas à produção de textos e à leitura. Outras pesquisas relatam sobre a deficiência de compreensão e o escasso hábito de leitura entre universitários - tanto da rede pública quanto da rede privada -, como os principais responsáveis no baixo desempenho acadêmico, já que a escolarização em nível universitário pressupõe uma considerável quantidade de trabalho intelectual, exigido em atividades de leitura, compreensão e expressão de conteúdos complexos (SAMPAIO; SANTOS, 2002).

Estudos demonstram que quanto mais aprimorada for a habilidade de compreensão em leitura, mais o estudante será capaz de ler criticamente as informações. No ensino superior essa habilidade é essencial para uma boa formação acadêmica, porque leva a formulação de hipóteses críticas sobre o que foi lido (OLIVEIRA; OLIVEIRA, 2007).

Tem-se, portanto, informação importante para os gestores e professores deste curso, no tocante ao hábito de escrever e interpretar texto neste grupo de estudantes ingressantes, que ficou acima da metade entre estes. Estratégias de apoio aos que tem dificuldades nestes quesitos e mesmo de aprimoramento para alguns, se fazem necessárias tendo em vista as competências estabelecidas no processo de aprendizagem desse curso em especial.

\section{Conclusão}

Ante o exposto, conclui-se que o perfil dos ingressantes no curso de enfermagem da Universidade Estadual de Londrina se faz semelhante as demais faculdades de enfermagem do Brasil, principalmente aos dados sociodemográfico. Deste modo, uma parcela expressiva é representada por mulheres, que pertencem à faixa etária dos 16 aos 18 anos, solteiras, sem filhos, possuindo um ou dois irmãos, procedentes de outras cidades - muitas dessas, vizinhas de Londrina - e residentes nas casas de seus genitores. Não apresentam vínculo empregatício, dependem economicamente de seus pais, sua renda familiar fica entre 5 a 10 salários mínimos, o transporte mais usado para chegar à universidade é o público, apresentam domínio da informática e possuem computador em suas casas. Grande maioria dos estudantes detém o hábito do estudo, as leituras favoritas são revistas e livros literários, preferem estudar sozinhos e são indiferentes ao horário de estudo. $\mathrm{O}$ ambiente de estudo silencioso é o preferido, o local mais requisitado para esta atividade é o quarto, a leitura silenciosa é a forma de estudo mais adotada. Relataram ter facilidade na escrita e mediana facilidade na interpretação de texto.

Por fim, considerando que a leitura e o estudo são meios essenciais para o bom desenvolvimento preconizado no Currículo Integrado, espera-se com a apresentação das informações deste estudo, subsidiar a gestão do curso e os professores no sentido de fomentar o desempenho acadêmico dos estudantes de enfermagem.

\section{Referências}

ANAStASIOU, L. G. C.; AlVES, L. P. Processos de ensinagem na Universidade: pressupostos para as estratégias de trabalho em aula. 10 ed. Joinville: UNISVILLE, 2012.

ARRUDA, E. N. T.; SANTOS, J. O.; OLIVEIRA, P. P.; MENDES, K. G. L.; COUTINHO, R. M. C. A análise do hábito de leitura de graduandos do curso de enfermagem de uma universidade privada de São Paulo. Journal of Health Sciences Instttute, São Paulo, v. 30, n. 4, p. 359-64, 2012.

BRASIL. Ministério da Educação. Conselho Nacional de Educação. Parecer CNE/CES 1 133/2001, de 07 de agosto de 2001. Estabelece as diretrizes curriculares nacionais dos cursos de graduação em enfermagem, medicina e nutrição. Diário Oficial da União, Brasília, 3 out. 2001. Seção 1, p. 131.

BRITO, A. M. R.; BRITO, M. J. M.; SILVA, P. A. B. Perfil sociodemográfico de discentes de enfermagem de instituições de ensino superior de Belo Horizonte, Escola Anna Nery. Revista de Enfermagem, v. 13, n. 2, p. 328-333, 2009. 
CHIRELLI, M. Q. O processo de formação do enfermeiro crítico-reflexivo na visão dos alunos do curso de Enfermagem da FAMEMA. Tese (Doutorado em Enfermagem) - Escola de Enfermagem de Ribeirão Preto, Universidade se São Paulo, 2002.

EURICH, R. B.; KLUTHCOVSKY, A. C. G. C. A avaliação da qualidade de vida de acadêmicos de graduação em enfermagem do primeiro e quarto anos: influência das variáveis sociodemográficas. Revista de Psiquiatria do Rio Grande do Sul, Porto Alegre, v. 30, n. 3, p. 211-220, 2008.

FERNANDES, J. D.; XAVIER, I. M.; CERIBELLI, M. I. P. F.; BIANCO, M. H. C.; MAEDA, D.; RODRIGUES, M. V. C. Diretrizes curriculares e estratégias para implantação de uma nova proposta pedagógica. Revista da Escola de Enfermagem da Universidade de São Paulo, São Paulo, v. 39, n. 4, p. 443-449, 2005.

GARANHANI, M. L.; VANNUCHI, M. T. O.; PINTO, A. C.; SIMÕES, T. R.; GUARIENTE, M. H. D. M. Integrated nursing curriculum in Brazil: A 13-Year Experience. Creative Education, Irvine, v. 4, n. 12b, p. 66-74, 2013.

GIL, A. C. Como elaborar projetos de pesquisa. 4. ed. São Paulo: Atlas, 2010.

KIKUCHI, E. M.; GUARIENTE, M. H. D. M. Currículo integrado: a experiência do curso de enfermagem da Universidade Estadual de Londrina. Londrina: UEL, 2014.

MARTINS, C.; KOBAYASHI, R. M.; AYOUB, A. C.; LEITE, M. M. J. Perfil do enfermeiro e necessidades de desenvolvimento de competência profissional. Texto Contexto Enfermagem, Florianópolis, v. 15, n. 3, p. 472-478, 2006.

MEIRA, M. D. D.; KURCGANT, P . Avaliação da formação de enfermeiros segundo a percepção de egressos. Acta Paulista de Enfermagem, São Paulo, v. 21, n. 4 , p. 556-561, 2008.

OLIVEIRA, R. A. M; OLIVEIRA, K. L. Leitura e condições de estudo em universitários ingressantes. PSIC, São Paulo, v. 8, n. 1, p. 51-59, 2007.
PISAMPAIO, I. S.; SANTOS, A. A. A. Leitura e redação entre universitários: avaliação de um programa de intervenção. Psicologia em Estudo, Maringá, v. 7, n. 1, p. 31-38, 2002.

SILVA, M. J. M.; SANTOS, A. A. A. A avaliação da compreensão em leitura e o desempenho acadêmico de universitários. Psicologia em Estudo, Maringá, v. 9, n. 3, p. 459-467, 2004.

SPÍNDOLA, T.; MARTINS, E. R. C.; FRANCISCO, M. T. R. Enfermagem como opção: perfil de graduandos de duas instituições de ensino. Revista Brasileira de Enfermagem, Brasília, v. 61, n. 2, p. 164-169, 2008.

SUZUKI, J. T. F. (Org.). TCC: elaboração e redação. Londrina: Redacional Livraria, 2009.

UNIVERSIDADE ESTADUAL DE LONDRINA. Resolução CEPE $n^{\circ}$ 0256/2009 de 11 de dezembro de 2009. Reformula o projeto pedagógico do curso de enfermagem, a ser implantado a partir do ano letivo de 2010. 2010. Disponível em: <http://www. uel.br/prograd/docs_prograd/resolucoes/2009/ resolucoes_259_09.pdf $>$. Acesso em: 15 set. 2013.

XAVIER, A. C. Letramento digital: impactos das tecnologias na aprendizagem da Geração Y. Calendoscópio, São Leopoldo, v. 9, n. 1, p. 3-14, 2011.

WetTeriCH, N. C.; MElO, M. R. A. C. Perfil sociodemográfico do aluno do curso de graduação em enfermagem. Revista Latino Americana Enfermagem, Ribeirão Preto, v. 15, n. 3, 2007. Disponível em: <http://www.scielo.br/pdf/rlae/ v15n3/pt_v15n3a07.pdf.>. Acesso em: 20 set. 2013. 